\title{
The behaviour of anchor plates in sand
}

\author{
R. K. ROWE and E. H. DAVIS (1982). Géotechnique 32, No. 1, 25-41
}

\section{Dr R. C. Harvey, Sunderland Polytechnic}

Soil-anchor interaction has become a topic of increasing importance, particularly as the scope of anchor technology has widened to include applications in the oflshore field (Harvey, Burley \& Nath, 1978; McCormick, 1979).

Reported tests on model anchors justifiably pay a good deal of attention to the size and mode of preparation of the soil bed, together with the bed properties before and during the testing procedure. Often a comparison with field tests is desirable and so the reduction of scale effects (Tsangarides, 1978), together with an appreciation of the extent of the zone of disturbance (Andreadis, Harvey \& Burley, 1981), during anchor testing must be tempered with the physical and technical efforts involved in the soil bed preparation. For example, in order to test $127 \mathrm{~mm}$ dia. anchor plates vertically loaded in a dense sand (Andreadis et al., 1981), and bearing in mind that the areas of disturbance during deep anchor testing could extend beyond ten anchor diameters (Meyerhof \& Adams, 1968), a test container $2.44 \mathrm{~m}$ in diameter was used. Soil pressure gauges at the tank wall indicated soil pressure changes during anchor testing but, as these changes were comparatively small, it was considered that the tank was of an appropriate size.

For the Authors' tests a tank size was used in which the boundaries of the physical model were considerably closer than the eight anchor widths of their theoretical model. Moreover it was not made clear how the anchors were placed with respect to the boundaries, i.e. whether the longer side of the anchor plate was placed parallel to the longer or shorter side of the tank. The influence of the soil bed boundaries on the Authors' physical tests is therefore questionable, as is the compatibility with the theoretical modelling, particularly for the anchors tested with the axis horizontal.

As regards the preparation of the soil bed, a number of processes have been used, e.g. raining, stirring, tamping and vibratory techniques (Hanna \& Carr, 1971; Maddocks, 1978; Andreadis, Harvey \& Burley, 1979). All methods of preparation need careful monitoring to achieve a

CCC article-fee code:

0016-8505/83/010073-74S0.40. suitable bed and it is helpful to measure the properties of the bed before and during testing. Soil pressure measurements have shown considerable variations. For example, a range of cocfficients of soil pressure of $0.25-0.60$ has been found for beds prepared by raining/pouring techniques.

Why did the Authors choose a raining/pouring technique for bed preparation? Had the bed properties been measured and variations found of the order indicated, how would the accuracy of the theoretical predictions have been affected?

The Authors have suggested a failure criterion based on the load which produces four times the displacement that would have occurred had the soil remained elastic. It is recognized that this criterion has some advantages over more common definitions of local shear failure. Research into circular anchor plates subjected to repeated and sustained-repeated loads (Andreadis et al., 1981) has suggested a strain-dependent failure criterion based on the minimum movement of the anchor per loading cycle. Although this criterion varies with the relative depth of embedment (i.e. embedment depth/plate diameter ratio) and repeated loading levels, it is less sensitive to the latter. For example, failure displacements of approximately $0.05 D$ and $0.10 D$, where $D$ is the anchor plate diameter, have been established for anchors installed at relative depths of 4 and 8 respectively. Accumulated anchor movement in excess of the defined failure, or critical, displacement implies that failure of the anchor will take place fairly rapidly. Post repeated load testing demonstrated that anchors experiencing total displacements below the critical value, due to any package of loading, display negligible drops in their ultimate static capacities.

Based on this criterion, the design of embedded plate anchors (Andreadis \& Harvey, 1981) can be carried out using both load and displacement factors which are appropriate for a system of a required life subjected to irregular field loads of a sustained, repeated and sustained-repeated nature.

Has the work of the Authors, which included a number of repeated loading tests, given an indication as to the applicability of their $k_{4}$ failure criterion to anchor plates subjected to general loading conditions? 


\section{REFERENCES}

Andreadis, A., Harvey, R. C. \& Burley, E. (1979). Embedded sea bed anchors subjected to repeated loading. Trans. R. Instn Nav. Archit. 121, 179-189.

Andreadis, A., Harvey, R. C. \& Burley, E. (1981). Embedded anchor response to uplift loading. $J$. Geotech. Engng Div. Am. Soc. Civ. Engrs 107, GT 1, 59-78.

Andreadis, A. \& Harvey, R. C. (1981). A design procedure for embedded anchors. Appl. Ocean Res. 3, No. 4, 177-182.

Hanna, T. H. \& Carr, R. W. (1971). The loading behaviour of plate anchors in normally and overconsolidated sands. Proc. 4 th Conf. Soil Mech., Budapest, 589-600.

Harvey, R. C., Burley, E. \& Nath, B. (1978). The development of an embedded sea bed anchor to provide multi-directional restraint. Proc. Int. Offshore Conf., Brighton, 97-107.

McCormick, M. E. (1979). Anchoring systems. Oxford: Perganion.

Maddocks, D. V. (1978). The behaviour of model ground anchors installed in sand and subjected to pull-out and repeated loading. $\mathrm{PhD}$ thesis, University of Bristol.

Meyerhof, G. G. \& Adams, J. I. (1968). The ultimate uplift capacity of foundations. Can. Geotech. J. 5, No. $4,225-244$.

Tsangarides, S. (1978). The behaviour of ground anchors in sand. PhD thesis, Queen Mary College, University of London.

\section{Reply from Professor Rowe}

Dr Harvey raises a valid point when he suggests that consideration should be given to the effect of lateral boundaries in model tests, particularly those in sand. Indeed, consideration was given to this effect. Rowe \& Booker (1979) produced theoretical solutions which show the effect of the distance $W$ to a smooth rigid lateral boundary on the elastic response of anchors with a vertical axis. These solutions indicate that the error due to the location of the lateral boundary would be less than $10 \%$. (In fact, because the actual boundary is not perfectly smooth, the error is probably considerably less than $10 \%$.) Elasto-plastic finite element analyses performed to indicate the effect of a rough rigid boundary also indicated an error of less than $10 \%$ for the model geometry and a relatively loose sand corresponding to that used in the model test. (The required distance to the lateral boundary is a function of the depth of sand beneath the anchor as well as the depth of embedment and the sand dilatancy.) Thus it was considered that the dimensions of the test box would be adequate. A larger box could have been used but it was considered that the advantages of this in terms of an increased distance to the lateral boundary would be outweighed by the increased difficulty in maintaining a uniform sample with the much larger volumes of sand that this would necessitate. The anchors in our test were oriented with the longer side parallel to the longer side of the sand box.

I agree that the dimensions of our test box would not be valid for anchors tested with a horizontal axis but we did not perform any such tests. All our tests were for anchors with a vertical axis. The results quoted for anchors with horizontal axes (Figs 21 and 22) were obtained from the published literature. Additional details are given in the references quoted in the Paper.

The primary object of the sand tests was to obtain what we considered to be reliable, repeatable results for rectangular anchors with a vertical axis in loose sand. The raining technique appeared to satisfy this objective adequately. As noted in the Paper, the standard deviation in the unit weight of the sand was $0.1 \mathrm{kN} / \mathrm{m}^{3}$ and, as shown in Table 2 and Fig. 16, the test results were as repeatable as could be reasonably expected. I doubt whether alternative sand placement techniques would provide better repeatability for these tests although I recognize that this technique is very dependent on the diligence of the technician placing the sand bed and may not have been as reliable if we had adopted a much larger sample.

We did perform a limited number of repeated loading tests and a number of observations are given in the Paper. However, we do not consider the number and range of these tests to be adequate to draw any firm conclusions regarding the applicability of the $k_{4}$ collapse load to situations involving a large number of repeated loadings. Cyclic loading of anchors is a subject which requires considerable theoretical and experimental research.

\section{REFERENCE}

Rowe, R. K. \& Booker, J. R. (1979). A method of analysis for horizontal anchors in an elastic soil. Int. $J$. Numer. Analyt. Meth. Geomech. 3, No. 2, 187-203. 